\title{
Certification of an Algorithm for Bessel Functions of Real Argument
}

\author{
David J. Sookne* \\ Institute for Basic Standards, National Bureau of Standards, Washington, D.C. 20234
}

(June 4, 1973)

The accuracy of routine BESLRI is certified.

Key words: Bessel functions; bit comparison; error bounds.

\section{Introduction}

Bessel function values $I_{n}(x)$ and $J_{n}(x)$ ( $x$ real), generated by BESLRI [1], ${ }^{1}$ were compared with check values. For $|x|<64$, these check values were calculated via the ascending series

$$
J_{n}(x)=\left(\frac{x}{2}\right)^{n} \sum_{k=0}^{\infty} \frac{\left(-x^{2} / 4\right)^{k}}{k !(n+k) !}, \quad I_{n}(x)=\left(\frac{x}{2}\right)^{n} \sum_{k=0}^{\infty} \frac{\left(x^{2} / 4\right)^{k}}{k !(n+k) !},
$$

using multiprecision arithmetic [2]. For $x \geqslant 64$, the asymptotic formulas for large argument were used:

$$
I_{n}(x) \sim \frac{e^{x}}{\sqrt{2 \pi x}}\left(1-\frac{(\mu-1)}{8 x}+\frac{(\mu-1)(\mu-9)}{2 !(8 x)^{2}}-\frac{(\mu-1)(\mu-9)(\mu-25)}{3 !(8 x)^{3}}+\cdots\right)
$$

where $\mu=4 n^{2}$, and error is controlled by 7.16 of [3], and

$$
J_{n}(x)=\sqrt{\frac{2}{\pi x}}\{P(n, x) \cos \chi-Q(n, x) \sin \chi\}
$$

where $\chi=x-\left(\frac{n}{2}+\frac{1}{4}\right) \pi$, and

$$
\begin{aligned}
& P(n, x) \sim 1-\frac{(\mu-1)(\mu-9)}{2 !(8 x)^{2}}+\frac{(\mu-1)(\mu-9)(\mu-25)(\mu-49)}{4 !(8 x)^{4}}+. . \\
& Q(n, x) \sim \frac{\mu-1}{8 x}-\frac{(\mu-1)(\mu-9)(\mu-25)}{3 !(8 x)^{3}}+\ldots .
\end{aligned}
$$

${ }^{1}$ Figures in brackets indicate the literature references at the end of this paper. 
with errors bounded hy the first neglected term [4, 9.2.9 and 9.2.10]. These were programmed in double precision. For $x \leqslant-64,-x$ was used as the argument, and the sign of the function value was determined from the equations

$$
J_{n}(-x)=(-1)^{n} J_{n}(x), \quad I_{n}(-x)=(-1)^{n} I_{n}(x) .
$$

The method used was that of bit comparison; the difference between the 60-bit mantissas of test and check values was expressed as a multiple, $m$, say, of the last bit. Such a bit error corresponds to a relative error between $m \cdot 2^{-60}$ and $m \cdot 2^{-59}$.

This test is too strict near a zero of $J_{n}(x)$, where absolute error is a more realistic measure. Thus for $n<|x|$, both mantissas were right-shifted so that the bit error described above was a multiple of the 60th binary place. These cases are given above the dashed line in the computer printout; statistics for this test are compiled separately.

A bit comparison test was also used to check the section of the code involving the two-term ascending series for small $|x|$.

The error return feature was tested exactly as in [5].

\section{The Bit Comparison Test}

To test the function $I_{n}(x)$, ten arguments were chosen in each interval

$$
A_{j}=\left\{x: 2^{j-1} \leqslant|x|<2^{j}\right\}, \quad j=-13(1) 10,
$$

the 60-bit mantissas of each $x$ being produced by a pseudorandom number generator [5]. The orders used in all cases were $n=0$ (1) 15 . The only modification occurred in the set $A_{10}$, for which $|x|$ was limited to 700 to avoid computer overflow in the final answers. Summary statistics for the 60-bit test on $I_{n}$ are:

373 results correct to 60 bits

583 results in error by 1 multiple of the last bit

383 results in error by 2 multiples of the last bit

288 results in error by 3 multiples of the last bit

232 results in error by 4 multiples of the last bit

196 results in error by 5 multiples of the last bit

176 results in error by 6 multiples of the last bit

130 results in error by 7 multiples of the last bit

1479 results in error by more than 7 multiples of the last bit

3840 (total)

The largest bit error was $(36)_{8}$, implying that at least 55 bits are correct in each case.

For the function $J_{n}(x)$, the set of intervals $A_{j}$ was expanded to $j=-13(1) 16$. Again, ten pseudorandom values were used in each interval, and the orders used were 0(1)15. Summaries for the tests are:

\section{Test on 60 Significant Bits $|x|<64$}

403 results correct to 60 significant bits

643 results in error by 1 multiple of the last bit

453 results in error by 2 multiples of the last bit

331 results in error by 3 multiples of the last bit 
232 results in error by 4 multiples of the last bit

171 results in error by 5 multiples of the last bit

109 results in error by 6 multiples of the last bit

68 results in error by 7 multiples of the last bit

82 results in error by more than 7 multiples of the last bit

2492 (total)

The largest bit error was $(15)_{8}$, showing that at least 56 bits are correct in each case.

Test on 60 Binary Places $|x|<64$

161 results correct to 60 places

200 results in error by 1 multiple of the last place

100 results in error by 2 multiples of the last place

85 results in error by 3 multiples of the last place

56 results in error by 4 multiples of the last place

46 results in error by 5 multiples of the last place

45 results in error by 6 multiples of the last place

14 results in error by 7 multiples of the last place

1 result in error by more than 7 multiples of the last place.

708 (total)

The largest bit error was $(10)_{8}$, showing that 56 binary places are correct in each case, and 57 places in all but one case.

In the test on 60 binary places for $|x| \geqslant 64$, the largest error was (422) 8 . This occurred in $J_{5}(x)$ and $J_{7}(x)$ for $x=59766.6$. . . Bearing in mind that about 60,000 back-recursion steps were executed, that each step included two multiplications and one addition, and also that the computer uses truncation in floating-point arithmetic rather than roundoff, we see that the error of $(422)_{8}$ $=274$ is quite reasonable. The other errors can be explained similarly.

For the test of the two-term ascending series, arguments of $2^{-16}$ and $2^{-100}$ were used; the former is just barely small enough for the truncation error to be neglected. Both $I_{n}(x)$ and $J_{n}(x)$ were tested with $n=0$ (1) 15 , and the largest error was 6 multiples of the last bit.

\section{Testing of Error Return}

The method used is the same as in [5]. Arguments used were $x=2^{k}$ where $k=-13$ (1) 9 for $I$ 's, and $k=-13$ (1) 13 for $J$ 's. In the test on Bessel function values of order NCALC-1, the largest error was 6 multiples of the last bit; most were zero.

In the test on order $[x]$, the largest error was $(46)_{8}$, which occurred in $J_{8192}(8192)$. This test value involved about 1600 more back-recursion steps than were required for the check value, so this error is quite reasonable. The other errors were $(35)_{8}$ for $x=4096$, zero for $x=2048,(12)_{8}$ for $x=1024$; for $x \leqslant 512$, the errors did not exceed 5 .

\section{Summary and Conclusions}

For $n=0(1) 15$ and the values of $x$ tested, BESLRI yielded $J_{n}(x)$ and $I_{n}(x)$ with either a relative error or an absolute error bounded by $10^{-14}$. The latter assessment applied to $J_{n}(x)$ when $n<|x|$. For $|x|<64$, the bound was $10^{-16}$. The error return and ascending series features were tested and found to be executed accurately in all cases. 
For other values of $n$ and $x$, similar accuracy can be expected, since the tests we have used include large and small values of $|x|$ and $\frac{|x|}{n}$, the former as large as $2^{16}$.

Calculations were performed on a UNIVAC 1108 under EXEC 2. All test values were calculated with double precision mantissa of 60 bits, corresponding to just over 18 figures. Subroutine executions took approximately $0.2 \mathrm{~N}$ milliseconds, where

$$
N=\max (|x|, \mathrm{NB})+10 .
$$

\section{Appendix: Algorithm BESLRI}

๑ ELT BESLCI, 1,730112, 51748

000001
000002
000003
000004
000005
000006
000007
000008
000009
000010
000011
000012
000013
000014
000015
000016
000017
000018
000019
000020
000021
000022
000023
000024
000025
000026
000027
000028
000029
000030
000031
000032
000033
000034
000035
000036
000037
000038
000039
000040
000041
000042
000043
000044
000045
000046
000047
000048
000049
000050
000051
000052
000053
000054

SUBROUT INE BESLCI! X, Y, NB, IZE, BR, BI, NCALC ) C THIS RUUTINE CALCULATES BESSEL FUNCTISNS I AND $J$ gF C COMPLEX ARGUMENT AND INTEGER ORDER.

c

c i

c

C

c

C $\mathrm{Y}$

C NB

EXPLANATIGN GF VARIABLES IN THE CALLING SEQUENCE

DOUBLE PRECISION REAL PART OF THE COMPLEX ARGUMENT FER WHICH I\#S OR J\#S ARE TO BE CALCULATED. IF I*S ARE TO BE CALCULATED, ABS(X) MUST NOT EXCEED EXPARG (WHICH SEE BELGW).

IMAGINARY PART OF THE ARGUMENT. IF J S ARE TO BE CALCULATED, ABS(Y) MUST NOT EXCEED EXPARG.

NB INTEGER TYPE. 1 * HIGHEST ORDER TO BE CALCULATED.

C IZE INTEGER TYPE. ZERE IF J IF $I * S$ SAR TO BE CALCULATED.

C BR DOUBLE PRECISION VECTOR OF LENGTH NB, NEED NGT BE C BR DOULL AREC BY USER, IF THE ROUTINE TERMINATES

C NERHALLY (NCALC-NB), IT RETURNS THE REAL PART OF

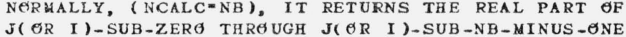
J (

BI IMAGINARY ANALOG OF BR.

C NCALC INTEGER TYPE, NEED NOT BE IN ITIALIZED BY USER. BEFORE USING THE RESULTS, THE USER SHøULD CHECK THAT NCALC=NB, I.E, ALL ORDERS HAVE BEEN CALCULATED TO THE DESIRED ACCURACY. SEE ERROR RETURNS BELOW.

EXPLANATI IN OF MACHINE-DEPENDENT CONSTANTS

NGIG DECIMAI, SIGNIFICANCE DESIRED. SHOULD BE SET TU IFIX( ALOG $10(2)$ *NBIT*1), WHERE NBIT IS THE NUMBER OF BITS IN TRE BANTISSA OF A DOUBLE PRECISION VARIABLE. SETTING NSIG HIGHER WILL INCREASE CPU TIME FITHOUT INCREASING ACCURACY, WHILE SETTING NSIG LOWER WILL DECREASE ACCURACY. IF ONLY SINGLE-PRECISION ACCURACY IS DESIRED, REPLACE NBIT BY THE NUSBER OF BITS IN THE MANTISSA OF A SINGLE-PRECISIGN VARIABLE. THE RELATIVE TRUNCATION ERROR IS LIUITED TO T=.5\#10 THE RELATIVE TRUNCATION ERROR IS LIATTED TO T-.5\#10 OH-NSIG NOR GRDER GREATER THAN ABS(Z), AND FOR ORDER LESS THAN AES( $Z$ ) (GENTRAL TEST), THE KLLATIVE ERRER LEAST 1. AND THE ABSOLUTE ERROR IS LIMITED TO T FOR LEAST 1, AND THE
SHS LLER VALUES.

NTEN LARGEST INTEGER K SUCH THAT 10\%\# IS MACHINEREPRESENTABLE IN DNUBLE PREC IS IøN.

C LARGEZ UPPER LIMIT ON THE MAGNITUDE OF $Z$. BEAR IN WIND C THAT IF ABS $(Z) \sim N$, THEN AT LEAST N ITERATIGNS OF TZE BACXWARD RECURSIEN WILE BE EXECUTED.

EXPARG LARGEST DGUBLE PRECISION ARGUMENT THAT THE LIBRARY DEXP REUTINE CAN HANDLE.

$$
\text { J.Res. } 77 \text { B } 3 \& 4-386
$$

00010

00020

00030

00040

00050

00060

00070

00080

00100

00110

00120

00130

00140

00150

00160

00170

00180

00200

00210

00220

00230

00240

00260

00270

00280

00290

00300

$003: 0$

00320
00330

00340

00350

00360

00370

00380

00330

00400

00410

00420

00430

00440

00450

00450

00470

00480

00490

00500

00510

00520

00540 
LET $G$ DENETE EITHER I OR J,

00570 ARE CALCULATED TO THE JESIRED ACCUKACY.

IF NCALC, LT, O, AN ARGUSENT IS $\triangle U T$ OF RANGE, NB, LE,

T IS OUT OF RANGE, NB.LE.

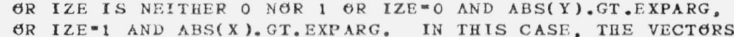
BR AND BI ARE NST CALCULATED, AND NCALC IS SET TO INO $(N B, O)-1$ SE NCALC.NE.NB.

NB.GT.NCALC.GT. 0 WILL. OCCUR IF NB.GT.MAGZ AND ABS(G SUB-NB-OF-Z/G-SUB-MAGX-EF-Z). LT, 10, $\#(N T E N / 2)$, I . E. NB IS NUCB GREATER THAN MAGZ. IN THIS CASE, BR(N) AND BI(N) are Calculated tó the desired accuracy For N.LE.NCAlC, BUT FOR NCALC.LT.N.LE.NB, PRECISION IS LOST. IF N.GT. NCALC AND ABS( G( $N C A L C-1) / G(N-1))$. EQ, $10 k k-K$, THEN THE LAST I SIGNIFICANT FIGURES OF G(N-1) $(=B R(N) ;+I * B I(N))$ ARE ERRONEUUS. IF THE USER WISHES TO CALCULATE G(N-1) TO HIGHER ACCURACY, HE SHEULD USE AN ASYMPTOTIC FORMULA FOR LARGE GRDER.

DQUBLE PRECISI ION

$X, Y, B R, B I, P R, P I, P L A S T R, P L A S T I, P E L D R, P O L D I, P S A V E R$,

2 PSAVEI, EXPARG, TEST, TOVER, TEMPAR, TE MPA I, TEMPBR, TEMPBI .

3 TENPCR, TEMPCI, SIGN, SUMR, SUMI, ZINVR, ZINVI

DIMENSIGIN BR(NB), BI(NB)

DATA NSIG, NTEN, LARGEZ, EXPARG/19,307,10000,7.D2/

TEXPAR $=D S Q R T(X * X+Y * Y)$

NAGZ $=$ IFIX ( SNGL (TEMPAR))

IF(NB,GT, O.AND, LAGZ,LE, LARGEZ.AND, ( (IZE,EQ.O.AND

1 DAES(Y),LE.EXPARG). OR. ( IZE,EQ.1.AND.DAES(X),LE.

2 EXPARG) $)$ GO TO 1

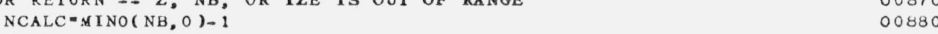
RETURN

$1 \operatorname{SIGN}=\operatorname{DBLE}(\operatorname{FL} \operatorname{LAT}(1-2 * \operatorname{IZE}))$ NCALC $=\mathrm{NB}$

C USE 2-TERM ASCENDING SERIES FER SMALL $Z$ 2.TERM ASCENDTNG SERTES FOR SMALL Z

C INITIALIZE THE CALCULATIGN 6 F THE NBMZ $=\mathrm{NB}-\mathrm{MAGZ}$ $\mathrm{N}=\mathrm{MAGZ} \cdot 1$ IF(DABS(X), LT.DABS( Y ) ) GO Tø 2 $\mathrm{Z}$ INVR $=1, D O /(\mathrm{X} * \mathrm{Y} * \mathrm{X} / \mathrm{X})$ $\mathrm{ZINVI}=-\mathrm{X} * \mathrm{ZINVR} / \mathrm{X}$ G\& $T \propto 3$

$2 \mathrm{ZINVI}=-1, \mathrm{DO} /(\mathrm{X} \bullet \mathrm{X} * \mathrm{X} / \mathrm{X})$

ZINVR=-XiZZINVI/Y

3 PLASTR=1.DO PLASTI $=0$. DO

$P R=S I G N * D B L E(F L \theta A T(2 * N)) * Z I N V R$

$P I=S I G N * D B L E(\operatorname{FLEAT}(2 * N)) * Z \operatorname{INVI}$

TEST-2, DO 1. D 1 \#\# N IC

$M=0$

IF( NBMZ,LT. 3) GO TO 6

C CALCULATE P\#S UNTIL N=NB-1.

TOVER $=1 . D 1 * *($ NTEN-NSIG)

CHECX FøR POSSIBLE OVERFL $\odot W$. NSTART $T$ NAGZ*2 
PLASTR $=$ PR

PR $=S I G N *($ DBLE $(F L \sigma A T(2 * N)) *($ PLASTR ZZINVR-PLASTI*ZINVI

5 CONTINUE $N=N E N D$

C CALCULATE SPECIAL SIGNIFICANCE TEST FOR NBMZ.GT.2.

TEMPBI = DKAX $1($ DABS ( PR ), DABS (PI))

TEMPBI $=$ TEMPEI \#DSORT (2,DO* $1 . D 1$ \#*NSIG \#DS CRT( ( (PR/TEMPBI)

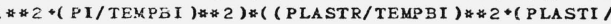

2 TEMPBI $) * 2) 1$

000132

000133

000134

000135

000136

000137

000138

000139

000140

00140

00141

(1)

000143

000144

000145

000146

000147

000148

000149

000150

00151

000153

000154

000155

000156

000157

000158

000159

000180

000161

000162

000164

000165

000166

000167

000168

$6 \quad \mathrm{~N}=\mathrm{N}+1$

POLDR-PLASTR

POLDI $=$ PLASTI

PLASTR $=P R$

PL.ASTI = PI

PR = SIGN* ( DBLE (FLOAT( 2*N)) *(PLASTR\#ZINVR-PLASTI\#ZINVI)

1 - $P$ PEDR )

$P I=S I G N *(D B L E(F L \theta A T(2 * N))$ * (PLASTI*ZINVR*PLASTR*ZINVI)

1 - PELDT)

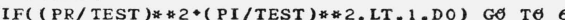

IF(M.EQ.1) GO TO 12

C CALCULATE STRICT VARIANT GF SIGNIFICANCE TEST, AND

C CALCULATE F*S UNTIL THIS TEST IS PASSED.

TEMPBI = DKAX $1($ DABS(PR ), DABS( PI ) )

TEMPBR - DSQRT( ( ( PR/TEKPBI )* \# 2 *(PI/TEMPBI )*\#2)/

1 ( ( PLASTR/TEMPBI)* *2・(PLASTI/TEAPBI)* *2))

TEM PBI $=$ DBLE $(F \operatorname{LOAT}(N+1)) / T E M P A R$

IF( TEMPBR 1 DO/TEKPBR, GT, 2, DO*TEMPBI) TEMPBR=TEMPB I

$1+D S Q R T(T E M P B I * * 2-1, D O)$

TEST=TEST/DSQRT (TEMPBR-1,DO/TEMPBR)

IF ( ( PR/TEST $) * 2+($ PI/TEST $) * 2-1$. DO $) 6,12,12$

NSTART $=\mathrm{N} *$

C Te AṼID OVERFL $\theta W$, NOFAALIZE P*S BY DIVIDING BY TUVER。

C CALCULATE P*S UNTIL UNNORLALIZED P WOULD OVERFLOW. $P R=P R / T E V E R$
$\mathrm{PI}=\mathrm{PI} / T$ TVER

PLASTR "PLASTR/TOVER

PLASTI = PLASTI/TOVER

PLASTI-PLAS

PSAVEI $=$ PI

TENFCR - PLASTR

TEUPCI = PLAST

TEST $=1 \cdot D 1 * *(2 * N S I G)$

$8 \mathrm{~N}=\mathrm{N}+1$

POLDR-PLASTR

POLDI= PLASTI

PLASTR $=$ PR 
15 TEMPAI $=-1 . \mathrm{DO} /(\mathrm{PI}+\mathrm{PR} *(\mathrm{PR} / \mathrm{PI}))$

TEMPAR $=-(P R * T E M P A I) / P I$

16 IF(IMAG.NE.0) GO TO 17

SUMR $=D B L E(F L O A T(M))$ ) TEMPAR SUNI-DELE(FLOAT(N)) * TEMPAI

$$
\text { GO TO } 18
$$

17 SUMR $=-D B L E(F L O A T(M))$ * TEMPAI SUMI=DBLE( FLOAT $(M))$ ) TEMPAR

$18 \mathrm{NEND}=\mathrm{N}-\mathrm{NB}$

IF ( NEND) $26,22,19$

C RECUR BACKWARD VIA DIFFERENCE EQUATION CALCULATING (BUT

C NOT STARING) BR(N) AND BI(N) UNTIL N=NB。

19 De $21 \quad L=1, N E N D$

$$
\begin{aligned}
& N=N-1 \\
& T E M P C R=T E M P B R \\
& T E M P C I=T E M P B I \\
& T E M P B R=T E M P A R
\end{aligned}
$$

TEMPBI = TEMPAI

$P R=\operatorname{DELE}(F \operatorname{LQAT}(2 * N)) * Z$ INVR

$P I=D B L E(F L O A T(2 * N)) * Z I N V I$

TEMPAR * PR *TEMPBR - PI *TEMPBI-S IGN \#TENPCR

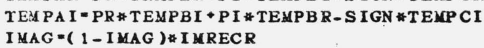

K=MLAST

MLAST $=$ M

$M=K \# M R E C U R$

IF( IMAG.NE, O) GO TE 20

SUMR $=$ SUNR $*$ DELE (FLAAT( M ) ) * TE MPA

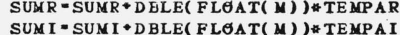
SUM I $=$ SUN I DO TO 21
GUMR

20 SUMR - SUMR -D BLE ( FLOAT( M) ) * TEMPAI

SUMI I - SUM I D D BLE ( FLOAT $(M))$ * TE MPAR

21 CONTINUE

C STORE BR(NB), BI(NB)

$22 \operatorname{BR}(N)=$ TEMPAR

IF (N.GT.1) GO TO 23

C NB=1. SINCE 2*TEMPAR AND 2\#TEXPAI WERE ADDED TG SUMR AND

C SUMI RESPECTIVELY, WE MUST SUBTRACT TEXPAR AND TEMPAI

$S U M R=S U L R-T E M P A R$

SUM I $=$ SUM
GO TO 35

C CAL CULATE AND STORE BR(NB-1), BI(NB-1) -

$23 \mathrm{~N}=\mathrm{N}-1$

$P R=D B L E(F L \theta A T(2 * N)) \# Z$ INVR

$P I=\operatorname{DBLE}(\operatorname{FLOAT}(2 \# N))$ Z INVI

$B R(N)=P R$ * TEMPAR-PI \# TEMPA I -S IGN *TENPBR

$B I(N)=P R$ * TEMPAI * P I * TEMPAR -S I GN *TENPBI

IF (N.EQ.1) Go TO 34

I $M A G=(1-I N A G)$ * IMR ECR

$\mathrm{K}=$ KLAST

YLAST $=M$
$Y=K \#$ M RECUR

IF(IMAG.NE.O) GO TO 24

SUMR-SUNR+DBLE( FLEAT( N)) \#BR(N) 
C N.LT, NB, S $\Theta$ STORE BR(N), BI(N), AND SET HIGHER ORDERS ZERO

BI $(N)=$ TEMPAI

$B I(N)=$ TEMPAI
NEND"-NEND

NEND"-NEND
DE $27 \quad L=1$, NEND

000295

000296

$27 \quad \mathrm{BI}(\mathrm{N}+\mathrm{L})=0 . \mathrm{DO}$

$\mathrm{NEND}=\mathrm{N}-2$

I F(NEND.EQ.0) GO TO 33

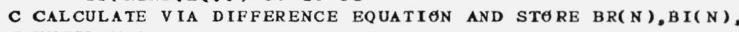
C UNTIL $N=2$

DO $32 \quad L=1, N E N D$

$\mathrm{N}=\mathrm{N}-1$

$P R=D B L E(F L \theta A T(2 * N)) * Z$ INVR

$\operatorname{PI}=\operatorname{DBLE}(\operatorname{FLOAT}(2 * N)) * \mathrm{ZINVI}$

$\operatorname{BR}(N)=\operatorname{PR} * \operatorname{BR}(N+1)-P I * B I(N+1)-\operatorname{SIGN} * \operatorname{BR}(N+2)$

$B I(N)=P R * B I(N+1)+P I * B R(N+1)-\operatorname{SIGN} B \operatorname{BI}(N+2)$

$I M A G=(1-I M A G)$ * I MRECR

$\mathrm{K}=\mathrm{MLAST}$

NLAST $=M$.

$M=K \# M R E C U R$

IF( IMAG. NE. O) GO TO 31

SUMR $=S U M R+D B L E(F L G A T(M) * B R,(N)$

SUM $I=\operatorname{SUMI} I \cdot \operatorname{DBLE}(F \operatorname{LOAT}(M)) \# B I(N)$

Ge TO 32

31 SUMR - SUMR-DBLE( FLOAT(M)) \#BI(N)

SUMI-SUMI-DBLE( FLOAT(M))*BR(N)

32 CONTINUE

C CAlCulate and Sture Br(1), Bi(1)

$33 B R(1)=2$. DO \# (BR( 2$) * Z I N V R-B I(2) * Z I N V I)-S I G N \# B R(3)$

BI $(1)-2 \cdot D O *(B R(2) * Z I N V I * B I(2) * Z I N V R)-S I G N * B I(3)$

34 SUMR=SUMR*BR( 1 ( SUMI-SUMI* BI( 1$)$

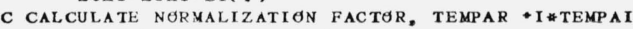

35 IF(IZE.EQ.1) GO TO 36

TEMPCR $=\operatorname{DBLE}($ F LOAT (IPJS) )\#X

TEMPCI $=$ DBLE $($ FLOAT $(-I P \sigma S)) * X$

TEMPCI $=D B$

36 TEM PCR - DBLE ( FLEAT( IPGS) )*X

TEMPCI - DBLE( FLEAT(IPOS) ) $Y$

37 TEMPCR - DEXP(TEMPCR)

TEMPBR $=$ DCOS( TEMPCI )

TEMPBI-DSIN (TEMPCI)

IF( DABS( SUMR). LT. DABS( SUMI)) GO TO 38

TEMPCI - SUMI/ SU IR

TEMPCR - (TEMPCR/SUMR $) /(1$. DO * TEMPC I *TEMPCI $)$

TEM PAR - TEMPCR ( TEMPBR -TEMP B I \#TEMPC I )

TEMPA I - TEMPCR ( TEMPBI - TEMP BR\#TEMPC I ) TEMPAI-

38 TEMPCI - SUMR/SUMI

TEXPCR $-($ TEMPCR/SUMI $) /(1$. DO +TEMPC I \#TEMPCI )

TEMPAR - TEMPCR ( TEMPBR

TEMPAI - TEXPCR (TEMPBI * TEMPCI-TEMPBR) 


\section{References}

[1] Algorithm BESLRI, see previous paper.

[2] Maximon, Leonard C., FORTRAN Program for Arbitrary Precision Arithmetic, unpublished data.

[3] Olver, Frank W. J., Error Bounds for Asymptotic Expansion with an Application to Cylinder Functions of Large Argument, in Asymptotic Solutions of Differential Equations and Their Applications, Calvin H. Wilcox, Editor (Wiley \& Sons, 1964).

[4] National Bureau of Standards, Handbook of Mathematical Functions, Nat. Bur. Stand. (U.S.), Appl. Math. Ser. 55 (1964).

[5] Certification of an algorithm for Bessel functions of complex argument, J. Res. Nat. Bur. Stand. (U.S.), in press.

(Paper 77B3\&4-386) 